\title{
The Role of Unrelated Donor Registries in HSCT
}

\author{
Irina Evseeva, Lydia Foeken, \\ and Alejandro Madrigal
}

\subsection{Introduction}

\subsubsection{From Anthony Nolan to 32 Million Volunteer Donors Worldwide}

Bone marrow donor registries (hereinafter referred to as registries) have been playing an important role in developing the treatment of HSCT for more than four decades. In 1974, the world's first registry was founded by Shirley Nolan in London. Shirley's son, a 3-year-old, Anthony, had been diagnosed with WiskottAldrich syndrome and needed a transplant. Following the example of Anthony Nolan, a large number of registries have been established around the world, mainly in the late 1980s to early 1990s and have increased over the years. The growing pool of donors has contributed to the development of stem cell transplantation as a treatment method and a field of science (Fig. 3.1).

I. Evseeva

Anthony Nolan, London, UK

L. Foeken

Word Marrow Donor Association (WMDA),

Leiden, The Netherlands

A. Madrigal $(\square)$

Anthony Nolan, London, UK

UCL Cancer Institute, Royal Free Campus,

London, UK

e-mail: a.madrigal@ucl.ac.uk

\subsubsection{Registry: Structure and Duties}

A registry is "an organisation responsible for coordination of the search for haematopoietic progenitor cells from donors (including cord blood) unrelated to the potential recipient" (WMDA International Standards 2017).

Registries play the main role in communication between the physician in the transplant centre and the healthcare professional contacting the donor at national and international level. Search requests for adult unrelated donors (AUDs) and cord blood units (CBUs) are usually sent to the national registry, which facilitates all stages of search and provision of the graft for a patient.

A typical registry performs different interrelated functions, including donor recruitment and management and search and interact with HLAtyping laboratories, apheresis and marrow collection centres, cord blood banks (CBBs), stem cell couriers and transplant centres.

Some registries recruit donors themselves, while others have an agreement with blood banks, donor centres or donor recruitment groups. The donor's or cord blood information is provided by the donor centre or CBB to a registry. The registry is responsible for listing the donors on the global database and handling communication with national and international transplant centres (through their national registries) if a potential match for a patient has been found.

The search for a suitable stem cell source is based on the HLA-type of the patient. 


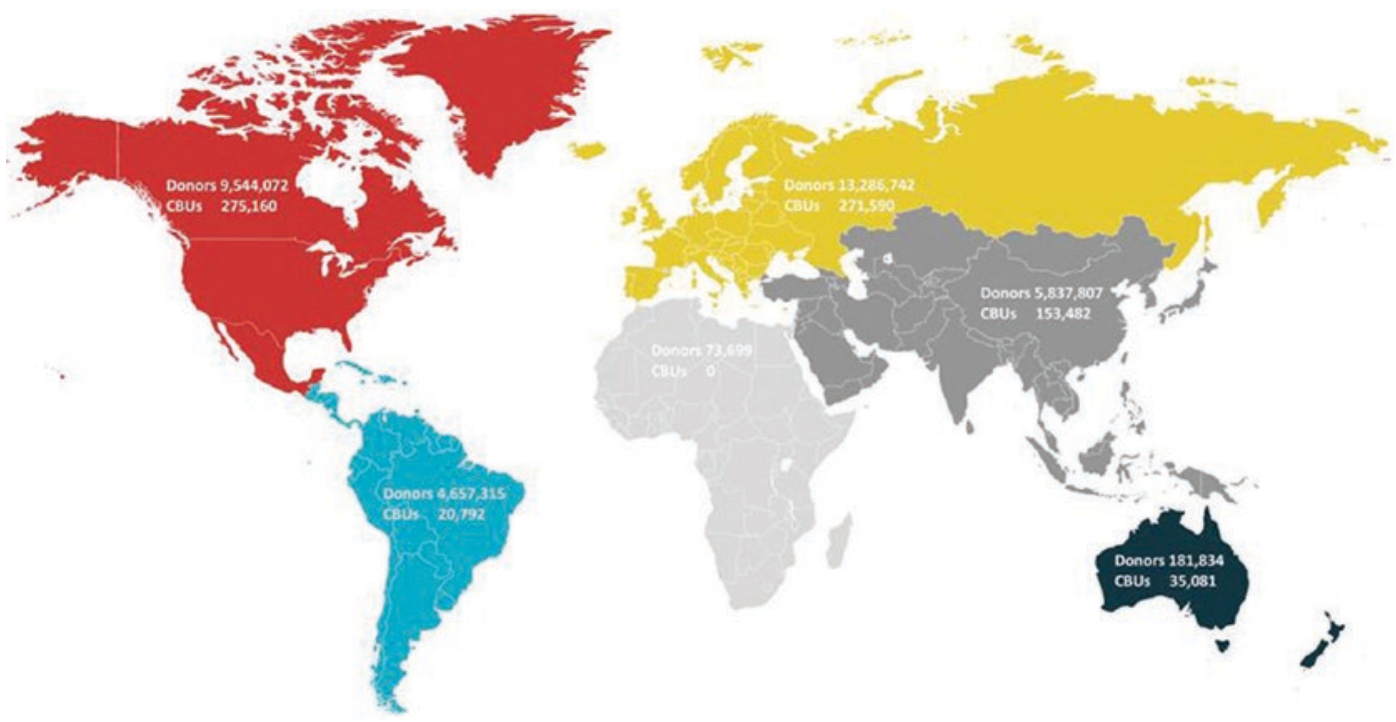

Fig. 3.1 Volunteer donors and cord blood units recruited around the wold (data from WMDA web page)

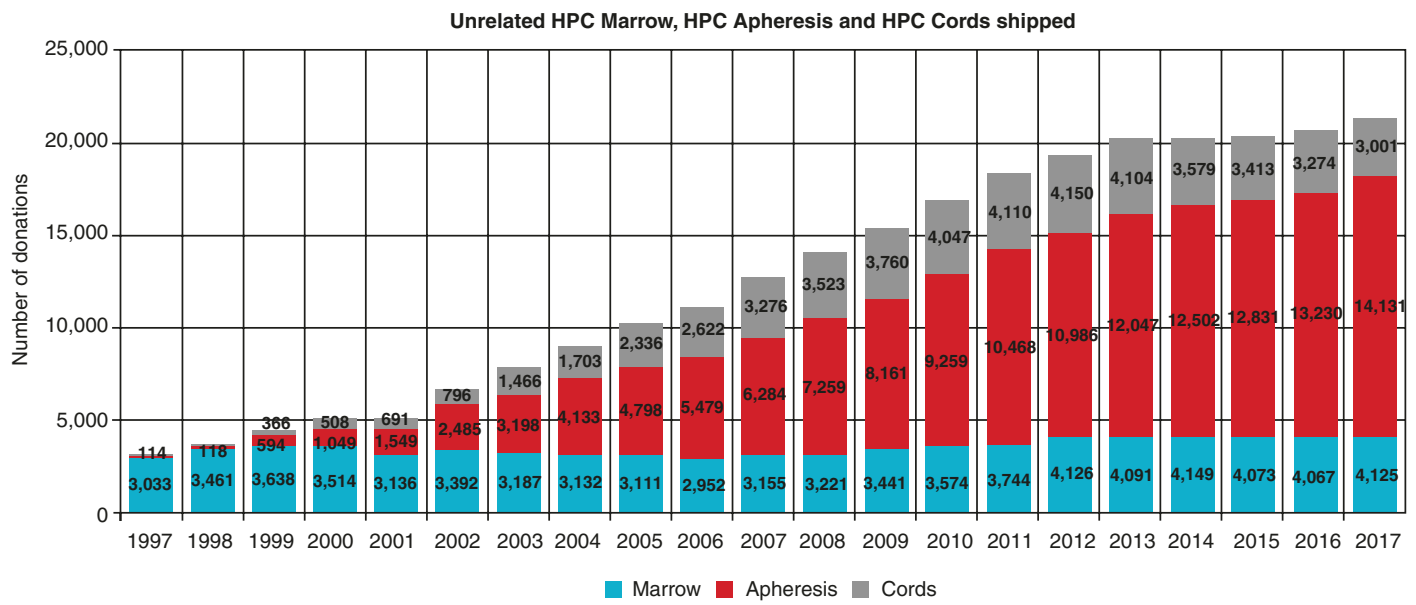

Fig. 3.2 Unrelated HSC from bone marrow, peripheral blood and cord blood shipped annually (data from WMDA)

Transplant centres and search coordinators within donor registries have access to the Search \& Match Service of WMDA (https://search.wmda. info/login), where they can register patient data and get a match list to see if there is a potential stem cell source in the global database.

When the transplant centre identifies a potentially matched stem cell source, the national registry will contact the relevant organisation and facilitate the delivery of stem cells for the patient. Annually, more than 20,000 stem cell products of different sources are shipped within and across borders to patients in need of a HSCT (see Fig. 3.2).

\subsection{Current Landscape}

\subsubsection{Ethnic Diversity and Chance to Find a Donor}

As of January 2018, more than 32 million potential AUDs and CBUs are listed in the global Search \& Match Service of WMDA. Almost 95\% 


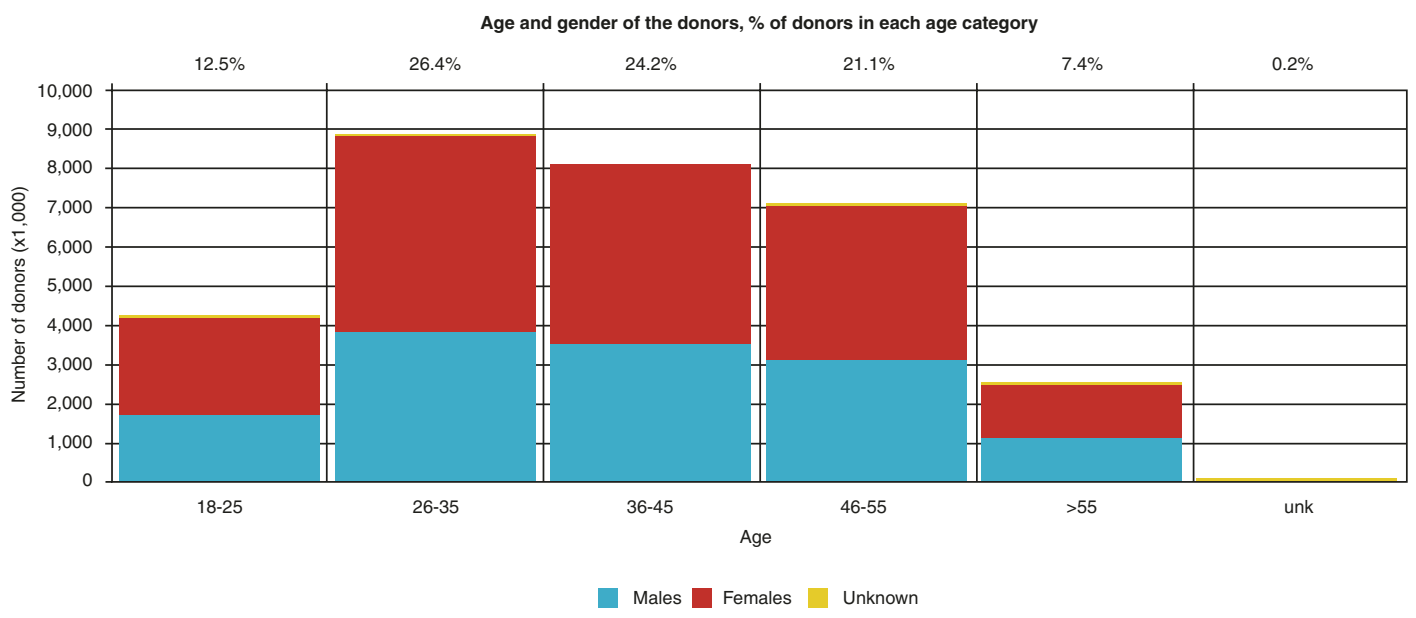

Fig. 3.3 Age and gender of unrelated donors and percentage of donors in each category

of these donors have DNA-based HLA-A, HLA-B and HLA-DRB1 phenotype presented, and more than half are listed with additional information on HLA-C, HLA-DQB1 and HLA-DPB1. Every year, registries across the world add approximately two million new volunteer donors to the worldwide pool, with the vast majority being HLA-typed at high and allelic level resolution.

The chance of finding a well-matched donor varies for patients belonging to different ethnic groups. In 2014, the National Marrow Donor Program (NMDP) study demonstrated that whereas approximately $75 \%$ of Caucasian patients are likely to identify an 8/8 HLAmatched AUD, the rate is much lower for ethnic minority and mixed-race patients. This is due to the higher genetic diversity of HLA haplotypes in African and Asian populations compared to Europeans and the lower representation and poorer availability of ethnic minority donors in the worldwide pool (Gragert et al. 2014).

\subsubsection{Donor Profile}

WMDA defines an unrelated donor as "a person who is the source of cells or tissue for cellular therapy product. Donors are unrelated to the patient seeking a transplant".

Donor centres recruit volunteer donors from 16 to 55 years of age with variations in individual policies. Although donors can remain on the database until they are 60 , donor centres try to recruit more young volunteers, as donor age has been proven to be linked to better HSCT outcomes (Kollman et al. 2016). According to the World Marrow Donor Association (WMDA) data, approximately $50 \%$ of donors listed globally are younger than 35 (see Fig. 3.3).

Medical suitability for donation, gender diversity, behaviour and psychological risks are constantly changing factors in donor recruitment and management. Donor centres align their policies with national and international standards and recommendations, including donor suitability guidelines produced by the WMDA on https://share. wmda.info/x/FABtEQ and published in 2014 (Lown et al. 2014).

Unrelated donors are acting voluntarily and altruistically and have a right to withdraw from the process at any stage. To avoid such cases, donor centres focus on informing volunteers about all aspects of donation, including risks, at the very early stage of recruitment. When a donor is identified as a potential match for a patient and is asked to provide a blood sample for verification or extended testing, healthcare professionals will have further detailed conversations with the donor addressing any possible questions and concerns. Full informed consent is usually given at the donor's medical, prior to the conditioning of the patient for transplant. 


\subsubsection{Recruitment, Retention and Data Confidentiality}

Recruiting volunteer donors is challenging. Registries and donor centres must ensure they are recruiting the preferred donors (usually younger donors) who are appropriately counselled to fully understand their commitment.

Registries and donor centres use a combination of methods to recruit potential donors including patient-related drives, targeting special groups, e.g. universities, uniformed services, engaging blood donors or online recruitment. The approach depends on the laws of the country and takes traditions, religion and habits into account. The same factors influence donor retention. Considering several options and alternative donors in urgent cases is a recommended practice.

By signing to a donor centre or registry, a potential donor agrees that his/her data are registered in the global database. The donor also provides biological material (blood sample, saliva or buccal swab) for tests, such as HLA typing and infectious disease markers, along with their personal details, in order to be searched as a match for a patient. The registry or donor centre has an obligation to adhere to national and international data protection laws and to keep donor personal and medical information confidentially and use it strictly in line with the donor's informed consent.

While social media helps enormously with donor recruitment and retention, it can present a challenge for confidentiality of both the donor and the recipient. Registries and donor centres in different countries have different policies on donor/patient post-donation contact and on the level of information provided to each other. These should be respected by all sides involved.

\subsection{Connections and Worldwide Collaboration}

\subsubsection{WMDA}

In 1988, three pioneers in the field of transplantation, Professors John M. Goldman (United Kingdom), E. Donnell Thomas (United States) and Jon J. van Rood (the Netherlands), informally initiated the WMDA, which became a formal organization in 1994. It is made up of individuals and organizations who promote global collaboration and best practices for the benefit of stem cell donors and patients requiring HSCT. It aims to give all patients worldwide equal access to highquality stem cells from donors, whose rights and safety are carefully protected.

\subsubsection{Quality and Accreditation}

In 2017, WMDA took the lead role in the merging of three key organizations: WMDA, BMDW and the NetCord Foundation. This allowed WMDA to streamline resources to provide a global platform for facilitating international search, to support members to develop and grow and to promote safety, quality and global collaboration through accreditation and standardisation. Eighty-four percent of AUDs available for search are provided by WMDA qualified/accredited registries (WMDA Annual Report 2017). WMDA accreditation of the registries along with FACTNetCord accreditation of the CBBs reassures recipients in the quality of product and services provided. A complete list of the accreditation status of organisations can be found on WMDA Share: https://share.wmda.info/x/4gdcAQ.

\subsubsection{Network Formalities}

All registries, donor centres and $\mathrm{CBBs}$ providing stem cells for HSCT nationally and internationally have legal agreements and contracts with each other within the network. The contracts cover legal, financial and ethical questions of collaboration in respect of obtaining, testing and shipment of stem cells.

\subsection{Challenges and Opportunities}

\subsubsection{Donor Attrition}

Time to transplant is reported to be a factor of overall survival (Craddock et al. 2011). Formal search for an unrelated donor on average takes 
about 2 months. However, more and more urgent search requests are made to the registries, where transplant centres are hoping to get a donor workup in weeks rather than months.

Not all potential donors listed on the database will be available for donation due to different reasons, including medical or personal circumstances or loss of contact with the registry. It varies in different countries. According to WMDA annual questionnaire, in 2017, the recommended target for donor availability at verification typing stage was $80 \%$ and at work-up stage $95 \%$. Registries and donor centres are working hard to keep in contact with their donors to have updated information to help reach the donor without delays. Some donor centres use private healthcare providers to speed-up blood sample collection and increase the number of apheresis centres in order to meet desirable turnaround times.

\subsubsection{Ethical Challenges}

HSCT is an evolving field of medical science. Volunteer donors can be asked to be a subject of research and clinical trials as part of their stem cell donation for a particular patient or not. In the majority of cases, this is covered by the informed consent given at the recruitment and donor medical stages, but in some cases, additional consent is required. It is the obligation of registries and donor centres to make sure that donors are well informed and free to withdraw.

\subsubsection{Donor Pool HLA Diversity}

Current trends in HSCT (with high requirements for patient/donor matching, complexity of standard and research protocols and a growing index of indications) present challenges for registries, donor centres and CBBs. Different strategies need to be applied to recruit not only a larger number of potential donors but also increase HLA diversity of the pool. As HLA allele and haplotype frequencies have population-specific patterns, there are limitations to how many different phenotypes can be obtained by adding new donors. In 2016, the WMDA reported no more than 50 different phenotypes per thousand new AUDs and CBUs submitted to the global database. This can be addressed by recruiting among ethnic minority groups or in parts of the world with a wider genetic diversity, e.g. Africa (see Fig. 3.4).

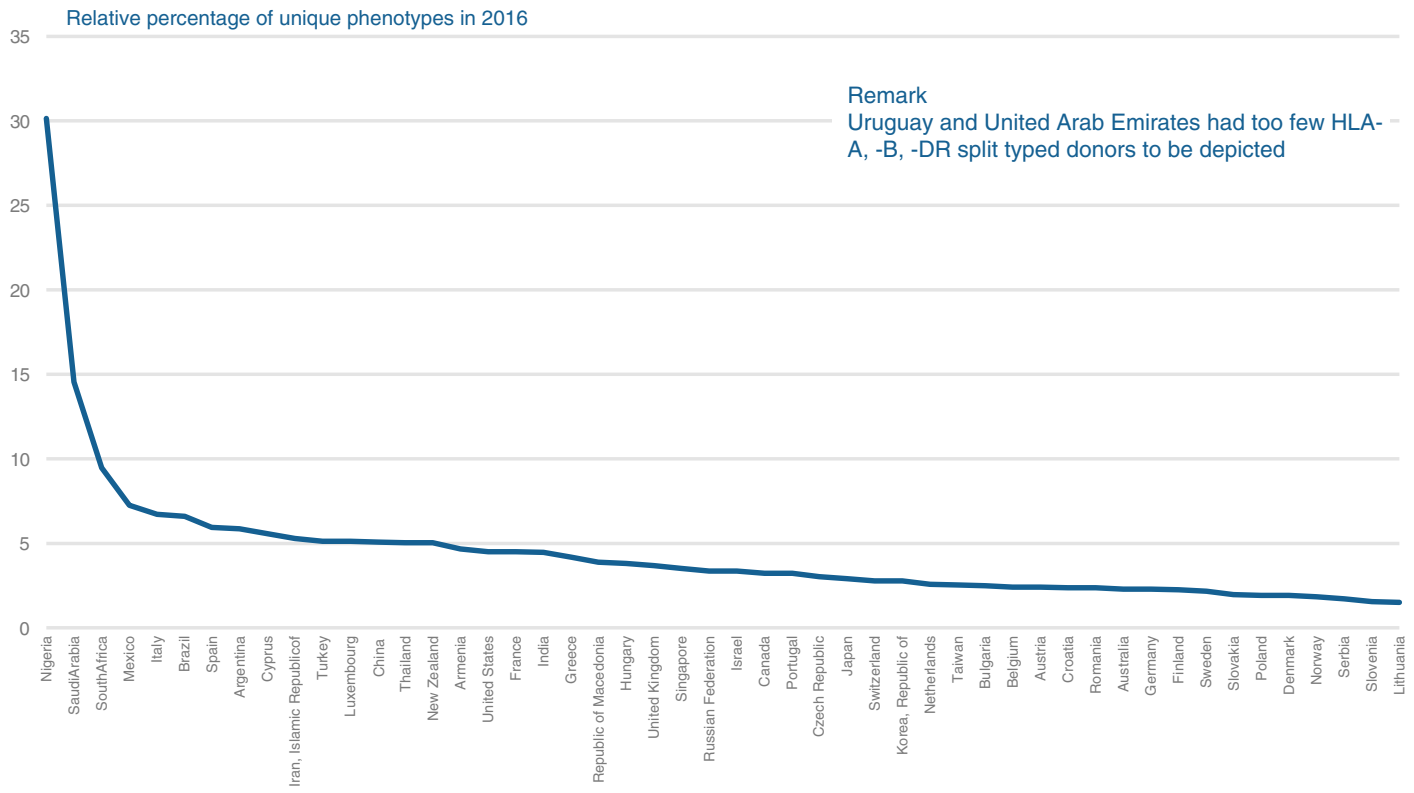

Fig. 3.4 Relative percentage of unique HLA-A, HLA-B and HLA-DR split phenotypes of stem cell donors per country contributed to the entire database of BMDW 
Although the majority of stem cell provisions worldwide are currently coming from Northern America and Europe, a few large registries arose in South America and Asia over recent years. WMDA is encouraging and supporting new and growing registries. The WMDA handbook: "A gift for life: the essential WMDA handbook for stem cell donor registries \& cord blood banks" (2016) provides all necessary information and advice for starting a registry in your country.

\subsection{Future Developments}

\subsubsection{New Level of HLA Matching}

As of January 2018, classic criterion for HLA matching with a patient is 10/10 at HLA-A, HLA-B, HLA-C, HLA-DRB1 and HLA-DQB1 for AUDs and 8/8 on HLA-A, HLA-B, HLA-C and HLA-DRB1 for CBUs, all at high-resolution level, with mismatches associated with inferior patient outcome (Shaw et al. 2017, Eapen et al. 2017). Many transplant centres are now considering HLA-DPB1 allele or epitope matching (Fleischhauer et al. 2012). There are also trends to include other genes like MICA and MICB in donor selection (Fuerst et al. 2016; Carapito et al. 2016; Kitcharoen et al. 2006).

The resolution of HLA matching is important. The advantage of allelic/ultrahigh-resolution HLA matching on OS and NRM compared to high-resolution level was presented by Anthony Nolan at the 2018 BMT Tandem meetings (Mayor et al. 2018). Full/extended gene sequencing results in fully phased phenotypes, thus significantly reduced allelic ambiguity, and can reveal mismatches not otherwise identified by highresolution typing.

Following these developments, some registries and donor centres have already implemented HLA allelic level typing for their donors and make additional non-HLA genetic information available for transplant centres at the search stage. It is expected that transplant centres will also be able to type patients at this level of resolution to achieve better matching and additional survival advantages.

\subsubsection{Related Donors Provision and Follow-Up}

Historically, registries have not been closely involved with the provision of related donors. However, in recent years, many registries have begun to support related donors internationally (i.e. where the patient is living in one country and their related donor is living in another) and domestically (e.g. where the patient and donor live far apart or the transplant centre cannot facilitate a collection). Some registries also provide support in following-up related donors postcollection and in providing information and support for related donors.

\subsubsection{Advisory Services Provided by Registries}

Nowadays, many registries are taking additional advisory roles in supporting transplant centres in stem cell searches as they accumulate knowledge and expertise over an ever-growing number of stem cell provisions. Working closely with clinical teams, national registries may offer advice and consultancy in donor selection, product quality evaluation, education and training.

As part of research and business development strategy, registries are looking at other products and services to further support HSCT. A range of cell therapy products may be provided along with standard stem cell donation or under a separate service agreement. 


\section{Key Points}

- International collaboration over the last four decades resulted in more than 32 million unrelated donors potentially available to donate stem cells for patients requiring HSCT.

- Donor search and provision are carried out via national registries to ensure quality and legal compliances.

- Unrelated donors act voluntarily and altruistically; their availability varies due to medical and personal reasons.

- Big efforts are made to increase HLA diversity of the donor pool to address the lower chance of finding a wellmatched donor for ethnic minority and mixed-race patients.

- Registries continue to develop HSCT by contributing to research, enhancing services and extending the range of cell products provided.

Acknowledgements The authors are grateful to Ms. Ann O'Leary, Ms. Nicola Alderson, Dr. Neema Mayor and Mrs. Pauline Dodi at Anthony Nolan for providing information and advising on the content of this chapter.

\section{References}

Carapito R, Jung N, Kwemou M, et al. Matching for the nonconventional MHC-I MICA gene significantly reduces the incidence of acute and chronic GVHD. Blood. 2016;128:1979-86.

Craddock C, Labopin M, Pillai S, et al. Factors predicting outcome after unrelated donor stem cell transplantation in primary refractory acute myeloid leukaemia. Leukemia. 2011;25:808-13.
Eapen M, Wang T, Veys PA, et al. Allele-level HLA matching for umbilical cord blood transplantation for non-malignant diseases in children: a retrospective analysis. Lancet Haematol. 2017;4:325-33.

Fleischhauer K, Shaw BE, Gooley T, et al. Effect of T-cell-epitope matching at HLA-DPB1 in recipients of unrelated-donor haematopoietic-cell transplantation: a retrospective study. Lancet Oncol. 2012;13:366-74.

Fuerst D, Neuchel C, Niederwieser D, et al. Matching for the MICA-129 polymorphism is beneficial in unrelated hematopoietic stem cell transplantation. Blood. 2016;128:3169-76.

Gragert L, Eapen M, Williams E, et al. HLA match likelihoods for hematopoietic stem-cell grafts in the US registry. N Engl J Med. 2014;371:339-48.

Kitcharoen K, Witt C, Romphruk A, et al. MICA, MICB, and $\mathrm{MHC}$ beta block matching in bone marrow transplantation: relevance to transplantation outcome. Hum Immunol. 2006;67:238-46.

Kollman C, Spellman SR, Zhang MJ, et al. The effect of donor characteristics on survival after unrelated donor transplantation for hematologic malignancy. Blood. 2016;127:260-7.

Lown RN, Philippe J, Navarro W, et al. Unrelated adult stem cell donor medical suitability: recommendations from the World Marrow Donor Association Clinical Working Group Committee. Bone Marrow Transplant. 2014;49:880-6.

Mayor NP, Hayhurst JD, Turner TR, et al. Better HLA matching as revealed only by next generation sequencing technology results in superior overall survival post-allogeneic haematopoietic cell transplantation with unrelated donors. Biol Blood Marrow Transplant. 2018;24(3):63-4.

Shaw BE, Mayor NP, Szydlo RM, et al. Recipient/donor HLA and CMV matching in recipients of T-celldepleted unrelated donor haematopoietic cell transplants. Bone Marrow Transplant. 2017;52:717-25.

WMDA Finance and Activities Report. WMDA, 2018. 2017. https://share.wmda.info

WMDA Handbook. A gift for life: the essential handbook for stem cell donor registries and cord blood banks (freely available for WMDA members); 2016.

WMDA International Standards for unrelated haematopoietic stem cell donor registries, January 2017. https://www. wmda.info/professionals/quality-and-accreditation/ wmda-standards/.

Open Access This chapter is licensed under the terms of the Creative Commons Attribution 4.0 International License (http://creativecommons.org/licenses/by/4.0/), which permits use, sharing, adaptation, distribution and reproduction in any medium or format, as long as you give appropriate credit to the original author(s) and the source, provide a link to the Creative Commons license and indicate if changes were made.

The images or other third party material in this chapter are included in the chapter's Creative Commons license, unless indicated otherwise in a credit line to the material. If material is not included in the chapter's Creative Commons license and your intended use is not permitted by statutory regulation or exceeds the permitted use, you will need to obtain permission directly from the copyright holder. 